\title{
Peroxisome Proliferator-Activated Receptor Modulation during Metabolic Diseases and Cancers: Master and Minions
}

\author{
Salvatore Giovanni Vitale, ${ }^{1}$ Antonio Simone Laganà, ${ }^{1}$ Angela Nigro, ${ }^{2}$ \\ Valentina Lucia La Rosa, ${ }^{3}$ Paola Rossetti, ${ }^{2}$ Agnese Maria Chiara Rapisarda, ${ }^{4}$ \\ Sandro La Vignera, ${ }^{5}$ Rosita Angela Condorelli, ${ }^{5}$ Francesco Corrado, ${ }^{1}$ \\ Massimo Buscema, ${ }^{2}$ and Rosario D'Anna ${ }^{1}$ \\ ${ }^{1}$ Unit of Gynecology and Obstetrics, Department of Human Pathology in Adulthood and Childhood "G. Barresi", \\ University of Messina, Messina, Italy \\ ${ }^{2}$ Unit of Diabetology and Endocrino-Metabolic Diseases, Hospital for Emergency Cannizzaro, Catania, Italy \\ ${ }^{3}$ Unit of Psychodiagnostics and Clinical Psychology, University of Catania, Catania, Italy \\ ${ }^{4}$ Department of General Surgery and Medical Surgical Specialties, University of Catania, Catania, Italy \\ ${ }^{5}$ Department of Clinical and Experimental Medicine-CRAMD (Research Centre of Motor Activity and \\ Metabolic Rehabilitation in Diabetes), University of Catania, Catania, Italy
}

Correspondence should be addressed to Salvatore Giovanni Vitale; vitalesalvatore@hotmail.com

Received 19 October 2016; Accepted 12 December 2016

Academic Editor: Daniele Fanale

Copyright (C) 2016 Salvatore Giovanni Vitale et al. This is an open access article distributed under the Creative Commons Attribution License, which permits unrestricted use, distribution, and reproduction in any medium, provided the original work is properly cited.

\begin{abstract}
The prevalence of obesity and metabolic diseases (such as type 2 diabetes mellitus, dyslipidaemia, and cardiovascular diseases) has increased in the last decade, in both industrialized and developing countries. This also coincided with our observation of a similar increase in the prevalence of cancers. The aetiology of these diseases is very complex and involves genetic, nutritional, and environmental factors. Much evidence indicates the central role undertaken by peroxisome proliferator-activated receptors (PPARs) in the development of these disorders. Due to the fact that their ligands could become crucial in future target-therapies, PPARs have therefore become the focal point of much research. Based on this evidence, this narrative review was written with the purpose of outlining the effects of PPARs, their actions, and their prospective uses in metabolic diseases and cancers.
\end{abstract}

\section{Introduction}

The prevalence of obesity and metabolic diseases (for example, type 2 diabetes mellitus (T2DM), dyslipidaemia, and cardiovascular diseases) has increased in the last decade, in both industrialized and developing countries. At the same time, we have observed similar increase in the prevalence of cancers. The aetiology of these disorders is very complex and involves genetic, nutritional, and environmental factors. There is much evidence that peroxisome proliferatoractivated receptors (PPARs) play a significant part in the progression of these diseases $[1,2]$.

Peroxisome proliferator-activated receptors (PPARs) are a group of ligand-activated nuclear hormone receptors (NRs), existing within the steroid receptor superfamily, which includes the receptors for thyroid hormones, retinoids, 1,25dihydroxyvitamin $\mathrm{D}_{3}$, and steroid hormones [3]. After binding with their agonists (natural or synthetic) in cytoplasm, PPARs heterodimerize with the retinoid acid receptor (RNR or NR2B) and translocate to the nucleus, subsequently binding to specific DNA regions termed peroxisome proliferator response elements (PPREs). Here they activate the transcription of numerous genes that play a role in mechanisms associated with glucose and lipid metabolism, body energy production, inflammation, cell cycle arrest, apoptosis, and DNA damage response $[4,5]$.

Currently, we know of three different types of PPARs $(\operatorname{PPAR} \alpha, \operatorname{PPAR} \beta / \delta$, and PPAR $\gamma$ ), which present many different features, such as tissue distribution, ligand specificities, and effects. The principal differences among PPARs are due 
to their structure; despite the DNA-binding domains being $80 \%$ identical, the ligand-binding domains are different. The biological effects of PPARs depend on their different ligand and the presence of several proteins that operate as coactivators or corepressors and whose presence may alter the expression of genes [6]. About this point, recent evidence suggests that the E6-associated protein (E6-AP) is an E3 ubiquitin ligase that affects the activity of other NRs: in particular, E6-AP is able to inhibit the ligand-independent transcriptional activity of PPAR $\alpha$ and PPAR $\beta$, with marginal effects on $\operatorname{PPAR} \gamma$, and decreased basal mRNA levels of $\operatorname{PPAR} \alpha$ target genes [7]. Similarly, Murine Double Minute 2 (MDM2), an E3 ubiquitin ligase, was identified as a PPAR $\alpha$ interacting protein that regulates the transcriptional activity of $\operatorname{PPAR} \alpha$ and $\operatorname{PPAR} \beta / \delta$, but not $\operatorname{PPAR} \gamma$ [8].

\section{PPAR $\alpha$ Role in Metabolic Diseases}

$\operatorname{PPAR} \alpha$ is expressed in large amounts in the liver, skeletal muscles, heart, intestinal mucosa, and brown adipose tissue, where it undertakes an important role in fatty acid metabolism, as well as glucose and lipid metabolism [9] $\operatorname{PPAR} \alpha$ activation induces the expression of genes involved in lipid and lipoprotein metabolism (apolipoprotein genes A1, A2, and A5), in fatty acid oxidation (acyl-coenzyme A oxidase and carnitine palmitoyltransferases I and II), in the desaturation of fatty acyl-CoA (delta-6-desaturase), in High Density Lipoprotein (HDL) metabolism (Phospholipid Transfer Protein), and in ketone synthesis (3-Hydroxy-3Methylglutaryl-CoA Synthase 2) [10]. Activated PPAR $\alpha$ also stimulates the expression of the fibroblast growth factor gene 21 (FGF21) and the angiopoietin-like protein gene 4 (ANGPLT4). In response to PPAR $\alpha$ activation, production of FGF21 in the liver begins, activating white adipose tissue lipolysis in order to provide nonadipose tissue with fatty acids as well as controlling ketogenesis in the liver with the purpose of procuring energy from fatty acids [11]. In partial agreement with these data, it was found that increased FGF21 expression was observed in the livers of $\operatorname{PPAR} \beta / \delta$-null mice and in mouse primary hepatocytes when this receptor was knocked down by small interfering RNA (siRNA) and that this increase was associated with enhanced protein levels in the heme-regulated eukaryotic translation initiation factor $2 \alpha$ (eIF2 $\alpha$ ) kinase (HRI) [12]. Recent studies indicate that the physiological fluctuations in lipoproteins lipase (LPL) activity are mediated by ANGPLT4 as well as the decrease in adipose LPL activity observed during intervals of fasting [13]. The natural and pharmacological ligands for $\operatorname{PPAR} \alpha$ are, respectively, omega- 3 fatty acids resulting from diet (such as linolenic, $\alpha$-linolenic, $\gamma$-linolenic, and arachidonic acids) and fibrate, normally used as potent hypolipidemic agents [14]. In the liver, PPAR $\alpha$ plays the role of lipid sensor, normally undergoing activation due to fatty acids and resulting in the increased burning of energy, the reduction of fat storage, and the prevention of steatosis; conversely, when PPAR $\alpha$ sensing is not efficient or when fatty acid concentration is decreased (for genetic, toxic, or metabolic causes), this causes a reduction in energy burning and the resulting lipotoxicity promotes hepatic steatosis and steatohepatitis [15].
These data were confirmed when liver and whole-body fatty acid homeostasis impairment was recently demonstrated in a hepatocyte-specific PPAR $\alpha$ knockout mouse model. Results included hepatic lipid accumulation (nonalcoholic fatty liver disease, NAFLD) and hypercholesterolemia during ageing [16]. In addition, mice conditionally expressing human PPAR $\delta$ demonstrated pronounced weight loss and promoted hepatic steatosis when treated with GW501516 (PPAR $\delta$-agonist) when compared to wild type mice [17]. Fibrates are weak PPAR $\alpha$ ligands; they reduce triglyceride (30-50\%) and very low-density lipoprotein (VLDL) levels through an increased rate of lipid uptake, lipoprotein lipasemediated lipolysis, and $\beta$-oxidation; in addition, fibrates also induce a modest increase in HDL cholesterol levels (5-20\%), secondary to the transcriptional induction of apolipoprotein A-I/A-II synthesis found in the liver [18]. In this way, they decrease the systemic availability of fatty acids as well as fatty acid uptake in muscles [19], consequently leading to fibrates reducing arteriosclerosis progression and cardiovascular events. They also increase insulin sensitization and reduce plasma glucose levels.

PPAR $\alpha$ activation by omega- 3 fatty acids results in an anti-inflammatory effect, caused in all probability by the inhibition of their own oxidation due to the activation of the nuclear factor kappa-light-chain-enhancers of activated $\mathrm{B}$ cells $(\mathrm{NF}-\kappa \mathrm{B})$. PPAR $\alpha$ also plays a key role in the mediation of the anti-inflammatory actions of palmitoylethanolamide, the natural amide of palmitic acid, and ethanolamide [20]. Recently, a PPAR $\alpha$ agonist (K-877) displaying high levels of potency and selectivity demonstrated optimal effects on atherogenic dyslipidemia [21]. In addition, a recent study indicated that statins, which are normally employed as cholesterol-lowering drugs, induce an increase in neurotrophin expression in the brain, as a result of their binding to a specific PPAR $\alpha$ domain independent of the mevalonate pathway. In a mouse model with Alzheimer's disease, the use of Simvastatin led to an increase in neutrophin expression, as well as an improvement in memory and learning [22].

\section{The Role of PPAR $\beta / \delta$ in Metabolic Diseases}

$\operatorname{PPAR} \beta / \delta$ is expressed ubiquitously, particularly in tissue which is metabolically active, such as the liver, skeletal and cardiac muscle, adipose tissue, and macrophages. Its involvement in the oxidation of fatty acids is crucial, and it improves lipid and cholesterol profiles. It plays a central role in the oxidation of fatty acids as well as improving lipid and cholesterol profiles, which reduces adiposity and prevents the development of obesity $[23,24]$. It also regulates glucose blood levels. In several animal studies, $\operatorname{PPAR} \beta / \delta$ acted as regulator of fat consumption; the deficiency of this receptor leads to obesity, while the activation of PPAR $\beta / \delta$ conversely results in resistance to this condition [25]. In the heart, in the presence of high-level dietary fat, $\operatorname{PPAR} \beta / \delta$ lowers lipid accumulation and increases glucose metabolism and consequently seems to be useful in diabetic cardiomyopathy, as it protects the heart against ischemia-reperfusion injury [26]. For all these reasons, PPAR $\beta / \delta$ agonists (GW501516, GW0742, and L-165041) could become a potential target 
in the treatment of metabolic disorders. However, adverse effects, particularly for PPAR $\gamma$ agonists, are also observed with the use of investigational PPAR agonists and even some approved drugs [27].

Recently, it was found that GW501516 significantly increased fatty acid oxidation and reduced the triglyceride amount in VLDL-loaded foam cells, suggesting a key role of $\operatorname{PPAR} \beta / \delta$ in modulating macrophage lipid overload [28]. Intriguingly, PPAR- $\delta$ agonist GW501516 decreases uptake of VLDL and expression of VLDL receptor at mRNA and protein levels through the regulation of miRNA-100 in Human Umbilical Vein Endothelial Cells [29]. Confirming the human findings, clear data from mouse model showed that $\operatorname{PPAR} \beta / \delta$-deficient mice fed with fructose exacerbated glucose intolerance and this led to macrophage infiltration, inflammation, enhanced mRNA and protein levels of CD36, and activation of the $\mathrm{c}$-Jun $\mathrm{N}$-terminal kinase pathway in white adipose tissue; fascinatingly, these effects were partially prevented by the PPAR $\beta / \delta$ activator GW501516 [30]. In addition, topical application of polymer-encapsulated GW501516 was found to have therapeutic wound healing activity, through stimulation of glutathione peroxidase 1 (GPxl) and catalase expression in fibroblasts: indeed, GPxl and catalase are known to scavenge excessive $\mathrm{H}_{2} \mathrm{O}_{2}$ accumulation in diabetic wound beds, preventing $\mathrm{H}_{2} \mathrm{O}_{2}$-induced extracellular matrix modification and facilitating keratinocyte migration [31]. Furthermore, $\operatorname{PPAR} \delta$ plays pivotal roles in wound healing by promoting fibroblast-to-myofibroblast differentiation via transforming growth factor (TGF)- $\beta / \mathrm{Smad} 3$ signalling: according to recent findings [32], GW501516activated PPAR $\delta$ increases the migration and contractile properties of human dermal fibroblasts and upregulates the expression of myofibroblast markers such as collagen I and fibronectin, with a concomitant reduction in expression of the epithelial marker E-cadherin.

Regarding GW0742, it was recently demonstrated that it can reverse the lung tissue damage induced by elastase in emphysema-model mice and improves respiratory function in mouse model: in particular, GW0742 increases the in vivo expression of surfactant proteins $A$ and $D$, which are known alveolar type II epithelial cell markers, reduces the average distance between alveolar walls in the lungs, and improves tissue elastance, as well as the ratio of the forced expiratory volume in the first 0.05 s to the forced vital capacity [33]. In addition, recent evidence suggests that GW0742 administration to mice fed in high-fat diet prevented the gain of body weight, heart and kidney hypertrophy, and fat accumulation: namely, it prevents the increase of in plasma levels of fasting glucose, glucose tolerance test, homeostatic model assessment of insulin resistance, and triglyceride; from the molecular point of view, it increases both protein kinase B (Akt) and endothelial nitric oxide synthase phosphorylation and inhibits the increase in caveolin-1/endothelial nitric oxide synthase interaction, ethidium fluorescence, nicotinamide adenine dinucleotide phosphate (NADPH) oxidase 1 , Toll-like receptor 4 , tumor necrosis factor- $\alpha$, and interleukin6 expression, and $\mathrm{I} \kappa \mathrm{B} \alpha$ phosphorylation [34].

Regarding the PPAR $\beta$ agonist L-165041, it was demonstrated that it induces vascular endothelial growth factor
(VEGF) (121), VEGF(165), and VEGF(189) expression in HPV (Human Papillomavirus) positive HeLa cells: considering the intrinsic connection between HPV-related cancer of uterine cervix and VEGF levels, it is possible that PPAR $\beta$ mediated pathway may play a key role in the development of this type of cancer [35]. Confirming these data, L-165041 was found to inhibit VEGF-stimulated angiogenesis by suppressing the cell cycle progression independently of PPAR $\delta$ : in particular, it reduces the number of endothelial cells in the $S$ phase and the expression levels of cell cycle regulatory proteins such as cyclin A, cyclin E, cyclin-dependent kinase (CDK) 2, and CDK4 [36]. Furthermore, a recent in vitro study found that L-165041 significantly inhibits high glucoseinduced interleukin- 6 and TNF- $\alpha$ production, receptor for advanced glycation end products expression, and NF- $\kappa \mathrm{B}$ translocation in human embryonic kidney 293 (HEK) cells; in addition, it increases superoxide dismutase expression and attenuates apoptosis in HEK and mesangial cells [37].

\section{PPAR $\alpha / \delta$ Role in Metabolic Diseases}

The dual PPAR $\alpha / \delta$ agonist (GFT-505-Elafibranor) seems to have potentially beneficial effects in the treatment of NAFLD. In 2013, Staels et al. [38] showed in a mouse model that GFT505 protects liver from steatosis, inflammation, and fibrosis. This agonist also improves liver markers, decreases hepatic lipid accumulation, and inhibits proinflammatory (IL-1, TNF $\alpha$ ) and profibrotic (transforming growth factor beta, tissue inhibitor of metalloproteinase 2, collagen type I, alpha 1 , and collagen type I, alpha 2 ) gene expression with a PPAR $\alpha$ dependent and independent mechanism [38]. In partial agreement with these data, it was recently found that Biliverdin reductase A protects against hepatic steatosis by inhibiting glycogen synthase kinase $3 \beta$ (GSK $3 \beta$ ) by enhancing serine 9 phosphorylation, which inhibits its activity: in particular, GSK3 $\beta$ phosphorylates serine 73 of the PPAR $\alpha$, which in turn increased ubiquitination and protein turnover, as well as decreasing activity [39].

In phase $2 \mathrm{a}$ trials (duration 8 weeks) involving twentytwo obese males with dyslipidemia, prediabetes, or T2DM, GFT505 reduced fasting plasma triglycerides, low-density lipoprotein (LDL) cholesterol, and liver enzyme concentrations improving peripheral insulin sensitivity and hepatic insulin sensitivity [40]. The liver-specific action of GFT505 was suggested by the fact that neither PPAR $\alpha$ nor PPAR $\delta$ target genes were induced in skeletal muscle. Recently, it was demonstrated that Elafibranor was capable of improving the histological features of severe and moderate nonalcoholic steatohepatitis (NASH) and presents a favorable safety profile [41].

\section{PPAR $\gamma$ Role in Metabolic Diseases}

PPAR $\gamma$ was the first to be cloned and studied in depth, due to its being the target of a class of antidiabetic drugs called thiazolidinediones (TZD). Currently, we know of three isoforms of PPAR $\gamma$ : PPAR $\gamma_{1}$ and PPAR $\gamma_{3}$, which are expressed in the liver, intestine, and spleen; PPAR $\gamma_{2}$ is present only in white and brown adipose tissue. Activated PPAR $\gamma$ induces the 
expression of many genes, essential for adipogenesis, energy balance, insulin sensitivity, lipid and glucose metabolism, and inflammation [42]. In adipocytes, PPAR $\gamma$ is necessary in order for adipose tissue to develop. PPAR $\gamma_{2}$ is a potent transcription activator and is triggered as a response to nutrient intake and obesity [43]. Indeed, mice deprived of PPAR $\gamma_{2}$ (obese POKO mice) presented higher levels of fat accumulation in adipocytes in comparison with normally obese mice fed an identical diet [44]. According to these data, $\operatorname{PPAR} \gamma_{2}$ is essential for preventing lipotoxicity by promoting the expansion of adipose tissue and an increased lipidbuffering capacity in liver, muscle, and pancreatic beta cells. A proliferative response of $\beta$-cells to insulin resistance is also promoted by PPAR $\gamma$ [45]. In adipocytes, activated PPAR $\gamma$ causes a both balanced and adequate adipocytokine secretion (adiponectin and leptin), which regulates the behavior of insulin when introduced to peripheral tissues (such as the liver, skeletal muscle). As a consequence, $\operatorname{PPAR} \gamma$ leads to improved insulin sensitivity in the entire body, additionally protecting the nonadipose tissue against excessive lipid levels [46]. Activated PPAR $\gamma$ induces the expression of genes that regulate the release, transport, and storage of fatty acid, such as the gene of LPL and fatty acid transporter CD36 [44]. PPAR $\gamma$ is also found in endothelial cells and vascular smooth muscle cells, where it seems to be an important factor in inflammation and atherosclerosis [47]. Polyunsaturated fatty acids are the natural ligand of PPAR $\gamma$; they increase glucose uptake and insulin sensitivity, but they do not have many effects on adipocytes differentiation [48]. As already mentioned, TZDs (pioglitazone, rosiglitazone) are synthetic agonists of PPAR $\gamma$ and are widely used for the treatment of type 2 diabetes. TZDs are also described as insulin sensitizing, as they indirectly induce a higher insulin-stimulated glucose uptake in adipocytes, hepatocytes, and skeletal muscle; they also reduce free fatty acids levels and increase lipid storage in adipocytes. In the liver, TZDs decrease fasting plasma glucose levels through the increase of insulin sensitivity and the inhibition of gluconeogenesis [34]. In the muscles, TZDs reduces postprandial glucose levels [49]. A typical effect of TZDs is weight gain, due (at least in part) to fat being redistributed from visceral depot to subcutaneous depot [49].

In diabetic patients, the two principal types of TZDs (rosiglitazone e pioglitazone) have different effects on cardiovascular outcomes. According to the data of a PROactive study, pioglitazone reduced $16 \%$ of cardiovascular complications compared to a placebo [50]. Conversely, rosiglitazone was linked with a significantly increased death rate due to cardiovascular causes; consequently, in 2010 the European Medicines Agency withdrew the usage of this molecule [51]. These existing differences between pio- and rosiglitazone are most likely due to their differing effects on lipid levels; in fact, pioglitazone leads to an increased level of HDL cholesterol whilst lowering levels of triglycerides and fasting fatty acids. Rosiglitazone increases total and HDL cholesterol but also LDL cholesterol, which is negatively associated with cardiovascular diseases [52].

Recently, a new synthetic antidiabetic drug (SR1664) was proposed: when compared to TZDs, it does not induce weight gain. SR1664, with respect to the classic agonist of PPAR $\gamma$, blocks only the phosphorylation of serine 273 by CDK5. In a recent study, CDK5 deficient mice (CDK5 KO) demonstrated a paradoxical augmentation of PPAR $\gamma$ phosphorylation at serine 273 by a protein kinase (extracellular signal-regulated kinase, ERK), normally suppressed by CDK5 [53], suggesting a key role in the modulation of the abovementioned pathways. Finally, as extensively summarized elsewhere [54, 55], it was showed that natural PPAR $\gamma$ ligands have different binding modalities to the receptor with respect to the full TZD agonists and can activate also PPAR $\alpha$ (as it occurs for genistein, biochanin A, sargaquinoic acid, sargahydroquinoic acid, resveratrol, and amorphastilbol) or the PPAR $\gamma$-dimer partner retinoid $\mathrm{X}$ receptor ( $\mathrm{RXR}$; as it occurs for the neolignans, magnolol, and honokiol).

\section{PPAR $\alpha$ and Tumorigenesis}

To date, many studies have analysed the role played by PPARs in the complex mechanism of tumorigenesis. Not all data are clear and PPARs seem to possess both positive and negative effects, depending on the type of tumor. In particular, it leads to negatively regulated colonic inflammation and proliferation. In an animal model of IL-10 $-/-$ mice, the inhibition of colitis was mediated by fenofibrate, increasing the PPAR $\alpha$ expression of lymphocytes, macrophages, and colonic epithelial cells and resulting in proinflammatory cytokine production, such as interleukin17 , interferon- $\gamma$, and chemokine (C-C motif) ligand 20 (CCL20), being inhibited [56]. In partial agreement with these results in the mouse model, it was recently found that activation of PPAR $\alpha$ through fenofibrate suppressed migration of oral cancer cells: in particular, differential protein profiling demonstrated that expressions of genes related to mitochondrial energy metabolism were either upregulated (Atp5g3, Cyc1, Ndufa5, Ndufa10, and Sdhd) or downregulated (Cox5b, Ndufal, Ndufb7, and Uqcrh), conforming the key role of $\operatorname{PPAR} \alpha$ activation and response in mitochondrial energy metabolism [57]. In addition, recent data suggests that the selective activation of $\operatorname{PPAR} \alpha$ by palmitoylethanolamide inhibits colitis-associated angiogenesis, decreasing VEGF release and new vessels formation, via the phosphatidylinositol 3-kinase/Akt/mammalian-target-of-rapamycin (mTOR) signalling pathway [58].

In breast cancer, the data are still not clear. In some studies, PPAR $\alpha$ inhibits breast cancer progression, promoting apoptosis of cancer cells through $\mathrm{NF} \kappa \mathrm{B}$ signalling. Recently, it was demonstrated that clofibrate presents a high chemosensitivity towards breast cancer cells, in all likelihood through the inhibition of NF- $\kappa \mathrm{B}$ and ERK1/2 activation, which lowers cyclin D1, cyclin A, and cyclin E and induces proapoptotic $\mathrm{P} 21$ levels [59]. In contrast, in other studies PPAR $\alpha$ promoted breast cancer progression by releasing leukotriene B4 that activates PPAR $\alpha$ in B cells, inducing the differentiation of B cells and metastasis [60].

Despite the fact that $\operatorname{PPAR} \alpha$ clearly acts in a tumordependent fashion [61], recent evidence suggests that its overexpression enhances cancer cell chemotherapy sensitivity, whereas silenced PPAR $\alpha$ decreased this event. In this regard, it is possible that it induces cell apoptosis by destructing 
B-cell lymphoma 2 (Bcl2): as summarized elsewhere [62], $\mathrm{PPAR} \alpha$ serves as an E3 ubiquitin ligase to govern $\mathrm{Bcl} 2$ protein stability; PPAR $\alpha$ binds to $\mathrm{BH} 3$ domain of $\mathrm{Bcl} 2$ and, subsequently, transfers K48-linked polyubiquitin to lysine-22 site of $\mathrm{Bcl} 2$ resulting in its ubiquitination and proteasomedependent degradation. Confirming these results, it was found that ectopic expression of PPAR $\alpha$ in hepatocarcinoma cells significantly suppressed cell proliferation and induced apoptosis by inhibition of NF- $\kappa \mathrm{B}$ promoter activity, diminution of phosphor-p65, phosphor-p50, and BCL2 levels, and enhancing IkB $\alpha$ protein [63].

\section{PPAR $\gamma$ and Tumorigenesis}

PPAR $\gamma$ or dual PPAR $\alpha / \gamma$ agonists, in rodent carcinogenicity studies, were frequently associated with the development of hemangioma or hemangiosarcoma, fibrosarcoma, bladder, and hepatic tumors [64], suggesting that these types of cancer are drug specific [65].

Recently, a hypothetical mechanism was proposed that could clarify the induction of liposarcoma by differing PPAR agonists: in this model, the first stage of tumor development is initiation, during which DNA damage ensues independent of PPAR activation. The second step, promotion, relies on PPAR and is defined by tumor cell recruitment, proliferation, and differentiation [44]. A multitude of in vitro and in vivo studies have demonstrated much evidence for the antitumor effects of natural and synthetic PPAR $\gamma$, since it seems to be upregulated in several human cancer lines. Indeed, recent data suggest that PPAR $\gamma$ ligands have an antitumorigenic effect in prostate cancer as a result of antiproliferative and prodifferentiation effects [66]. It would appear that TZDs possess protective effects in the development of pancreatic ductal adenocarcinoma, through improvement in insulin sensitivity and inflammation [67]. Interestingly, it was recently found that PPAR $\beta / \delta$ plays a role in regulating pancreatic cancer cell invasion through regulation of genes via ligand-dependent release of B-cell lymphoma- 6 and that activation of the receptor may provide an alternative therapeutic method for controlling migration and metastasis [68].

Despite the fact that data are still elusive, recent evidence from human follicular thyroid carcinoma seems to underlie a key role for paired box gene 8 (PAX8)/PPAR $\gamma$ fusion protein in enhancing in vivo angiogenesis through VEGF expression [69]. PPAR $\gamma$ has positive effects on breast cell cancer: it downregulates the expression of the C-X-C chemokine receptor type 4 (CXCR-4) gene, which is crucial in the growth and progression of cancer, as well as in the development of metastasis. This mechanism seems to be PPAR $\gamma$ dependent, because it could be reversed by GW9662, that is, a PPAR $\gamma$ antagonist [70]. In partial agreement with these results, it was recently found that $\gamma$-tocopherol-rich tocopherol decreased tumor volume and multiplicity in estrogen-induced breast cancer female rats, increasing the expression of PPAR $\gamma$ and its downstream genes, phosphatase and tensin homolog (PTEN), and p27 [71]. In addition, it was found that in vivo PPAR $\gamma$ expression in mammary stromal adipocytes attenuates breast tumorigenesis through breast cancer 1 (BRCA1) upregulation and decreased leptin secretion, and that 7,12-dimethylbenz[a]anthracene (DMBA) plus Rosiglitazone is able to reduce average mammary tumor volumes by 50\% [72]. Conversely, heterozygous or homozygous intestinal-specific PPAR $\gamma$ deficiency enhanced small intestine and colon tumorigenesis in $\mathrm{Apc}(\mathrm{Min} /+)$ mice [73]. Last but not least, robust data from myeloid-specific bitransgenic mouse model allow us to hypothesize that antiinflammatory PPAR $\gamma$ in myeloid-lineage cells plays a key role in controlling proinflammatory cytokine synthesis, myeloidderived suppressor cell expansion, immunosuppression, and the development of cancer [74]. Finally, recent evidence suggests that $\operatorname{PPAR} \gamma$ is able to induce apoptosis in lung cancer, although it can be inhibited by NR0B1, an orphan nuclear receptor whose knockdown reduces tumorigenic and antiapoptotic potential [75].

\section{PPAR $\delta$ and Tumorigenesis}

The role of PPAR $\delta$ in carcinogenesis is uncertain and seems to be context-dependent. In particular, PPAR $\delta$, through its anti-inflammatory effects, seems to prevent cancer before its development; conversely, after the development of cancer, the activation of PPAR $\delta$ promotes angiogenesis and cancer growth [76]. Clinical data suggest a strong association between PPAR $\delta$ and aggressive cancer; in particular, inverse correlation of PPAR $\delta$ expression with survival in gastrointestinal cancer has been noted [77]. In addition, PPAR $\delta$ is required for chronic colonic inflammation and colitisassociated carcinogenesis: specifically, the cyclooxygenase (COX)-2-derived prostaglandin E2 (PGE2) signalling mediates crosstalk between tumor epithelial cells and macrophages to promote chronic inflammation and colitis-associated tumor genesis [78]. In agreement with what reported in the previous chapters, high-fat diet is associated with increased colorectal cancer incidence, probably because many of its effects on stem and progenitor cell compartment are driven by a robust PPAR- $\delta$ program and contribute to the early steps of intestinal tumorigenesis [79]. In addition, recent evidence suggests that high-fat diet modifies the PPAR $\gamma$ pathway leading to disruption of microbial and physiological ecosystem in murine small intestine [80].

Recently, the expression of PPAR $\delta$ in breast cancer has been negatively linked with patient survival. In 2016, Wang et al. [81] showed that PPAR $\delta$ upregulation increases the expression of catalase and Akt in breast cancer cells and in this way cells are able to survive in harsh conditions (including in the presence of chemotherapies), promoting progression and metastasis. Not surprisingly, both the proinflammatory PGE2 and the BRCA1 tumor-suppressor gene were found to regulate aromatase expression [82] and, furthermore, pioglitazone is able to inhibit aromatase expression by inhibition of PGE2 signalling and upregulation of BRCA [83]. Finally, recent evidence suggests that PPAR $\delta$ modulates the migration and invasion of melanoma cells by upregulating Snail expression: in an elegant in vitro study, it was found that activation of PPAR $\delta$ by GW501516 significantly increased the migration and invasion of highly metastatic A375SM cells, but not that of low metastatic A375P cells, by upregulating Snail expression [84]. Despite the promising results, further 
studies are necessary in order to clarify the role of PPAR pathway modulation during cancer, also taking into account their paramount importance in regulating pro- and antiinflammatory activities $[85,86]$ as well as possible interaction with the immune system [87-89] and other metabolic determinants [90-93].

\section{Conclusion}

The fact that a link between PPAR signalling, metabolism, and cancer exists currently represents one of the most active research fields in the literature. As discussed in this review, PPARs have many important functions. PPARs could be considered the crossroads of obesity, diabetes, inflammation, and cancer. These molecules are extremely interesting and are capable of treating numerous metabolic and nonmetabolic diseases. Currently, not all the effects of PPARs are known or fully explained, especially those related to tumorigenesis. Further research is necessary to identify a high-affinity and high-specificity agonist in order to counteract the abovementioned diseases.

\section{Competing Interests}

The authors declare that there is no conflict of interests regarding the publication of this paper.

\section{References}

[1] G. S. Harmon, M. T. Lam, and C. K. Glass, "PPARs and lipid ligands in inflammation and metabolism," Chemical Reviews, vol. 111, no. 10, pp. 6321-6340, 2011.

[2] J.-C. Fruchart, "Peroxisome proliferator-activated receptoralpha (PPAR $\alpha)$ : at the crossroads of obesity, diabetes and cardiovascular disease," Atherosclerosis, vol. 205, no. 1, pp. 1-8, 2009.

[3] J. Berger and D. E. Moller, "The Mechanisms of Action of PPARs," Annual Review of Medicine, vol. 53, no. 1, pp. 409-435, 2002.

[4] S. Kersten, B. Desvergne, and W. Wahli, "Roles of PPARS in health and disease," Nature, vol. 405, no. 6785, pp. 421-424, 2000 .

[5] B. Desvergne and W. Wahli, "Peroxisome proliferator-activated receptors: nuclear control of metabolism," Endocrine Reviews, vol. 20, no. 5, pp. 649-688, 1999.

[6] T. M. Willson, P. J. Brown, D. D. Sternbach, and B. R. Henke, "The PPARs: from orphan receptors to drug discovery," Journal of Medicinal Chemistry, vol. 43, no. 4, pp. 527-550, 2000.

[7] L. Gopinathan, D. B. Hannon, R. W. Smith III, J. M. Peters, and J. P. Vanden Heuvel, "Regulation of peroxisome proliferatoractivated receptors by E6-associated protein," PPAR Research, Article ID 746935, 2008.

[8] L. Gopinathan, D. B. Hannon, J. M. Peters, and J. P. Vanden Heuvel, "Regulation of peroxisome proliferator-activated receptor- $\alpha$ by MDM2," Toxicological Sciences, vol. 108, no. 1, pp. 48-58, 2009.

[9] J. K. Reddy and M. S. Rao, "Lipid metabolism and liver inflammation. II. Fatty liver disease and fatty acid oxidation," American Journal of Physiology-Gastrointestinal and Liver Physiology, vol. 290, no. 5, pp. G852-G858, 2006.
[10] A. Shah, D. J. Rader, and J. S. Millar, "The effect of PPAR- $\alpha$ agonism on apolipoprotein metabolism in humans," Atherosclerosis, vol. 210, no. 1, pp. 35-40, 2010.

[11] T. Inagaki, P. Dutchak, G. Zhao et al., "Endocrine regulation of the fasting response by PPAR $\alpha$-mediated induction of fibroblast growth factor 21," Cell Metabolism, vol. 5, no. 6, pp. 415-425, 2007.

[12] M. Zarei, E. Barroso, R. Leiva et al., "Heme-regulated eIF2 $\alpha$ kinase modulates hepatic FGF2 1 and is activated by PPAR $\beta / \delta$ deficiency," Diabetes, vol. 65, no. 10, pp. 3185-3199, 2016.

[13] W. Dijk and S. Kersten, "Regulation of lipoprotein lipase by Angptl4," Trends in Endocrinology and Metabolism, vol. 25, no. 3, pp. 146-155, 2014.

[14] S. Neschen, K. Morino, J. Dong et al., "n-3 fatty acids preserve insulin sensitivity in vivo in a peroxisome proliferator-activated receptor- $\alpha$-dependent manner," Diabetes, vol. 56, no. 4 , pp. 1034-1041, 2007.

[15] A. Montagner, A. Polizzi, E. Fouché et al., "Liver PPAR $\alpha$ is crucial for whole-body fatty acid homeostasis and is protective against NAFLD," Gut, vol. 65, no. 7, pp. 1202-1214, 2016.

[16] E. Ip, G. C. Farrell, G. Robertson, P. Hall, R. Kirsch, and I. Leclercq, "Central role of PPAR $\alpha$-dependent hepatic lipid turnover in dietary steatohepatitis in mice," Hepatology, vol. 38, no. 1, pp. 123-132, 2003.

[17] W. G. Garbacz, J. T. J. Huang, L. G. Higgins, W. Wahli, and C. N. A. Palmer, "PPAR $\alpha$ is required for PPAR $\delta$ action in regulation of body weight and hepatic steatosis in mice," PPAR Research, vol. 2015, Article ID 927057, 15 pages, 2015.

[18] B. Staels, J. Dallongeville, J. Auwerx, K. Schoonjans, E. Leitersdorf, and J.-C. Fruchart, "Mechanism of action of fibrates on lipid and lipoprotein metabolism," Circulation, vol. 98, no. 19, pp. 2088-2093, 1998.

[19] M. P. Mosti, M. Ericsson, R. G. Erben, C. Schüler, U. Syversen, and A. K. Stunes, "The PPAR $\alpha$ agonist fenofibrate improves the musculoskeletal effects of exercise in ovariectomized rats," Endocrinology, vol. 157, no. 10, pp. 3924-3934, 2016.

[20] J. Lo Verme, J. Fu, G. Astarita et al., "The nuclear receptor peroxisome proliferator-activated receptor- $\alpha$ mediates the antiinflammatory actions of palmitoylethanolamide," Molecular Pharmacology, vol. 67, no. 1, pp. 15-19, 2005.

[21] Z.-M. Liu, M. Hu, P. Chan, and B. Tomlinson, "Early investigational drugs targeting PPAR- $\alpha$ for the treatment of metabolic disease," Expert Opinion on Investigational Drugs, vol. 24, no. 5, pp. 611-621, 2015.

[22] A. Roy, M. Jana, M. Kundu et al., "HMG-CoA reductase inhibitors bind to PPAR $\alpha$ to upregulate neurotrophin expression in the brain and improve memory in mice," Cell Metabolism, vol. 22, no. 2, pp. 253-265, 2015.

[23] Y. Wang, C. Lee, S. Tiep et al., "Peroxisome-proliferatoractivated receptor $\delta$ activates fat metabolism to prevent obesity," Cell, vol. 113, no. 2, pp. 159-170, 2003.

[24] J. Berger, M. D. Leibowitz, T. W. Doebber et al., "Novel peroxisome proliferator-activated receptor (PPAR) $\gamma$ and PPAR $\delta$ ligands produce distinct biological effects," The Journal of Biological Chemistry, vol. 274, no. 10, pp. 6718-6725, 1999.

[25] R. A. Ngala, C. J. Stocker, A. G. Roy et al., "A new, highly selective murine peroxisome proliferator-activated receptor $\delta$ agonist increases responsiveness to thermogenic stimuli and glucose uptake in skeletal muscle in obese mice," Diabetes, Obesity and Metabolism, vol. 13, no. 5, pp. 455-464, 2011. 
[26] B. Yu, C. Chang, H. Ou, K. Cheng, and J. Cheng, "Decrease of peroxisome proliferator-activated receptor delta expression in cardiomyopathy of streptozotocin-induced diabetic rats," Cardiovascular Research, vol. 80, no. 1, pp. 78-87, 2008.

[27] F. A. Monsalve, R. D. Pyarasani, F. Delgado-Lopez, and R. Moore-Carrasco, "Peroxisome proliferator-activated receptor targets for the treatment of metabolic diseases," Mediators of Inflammation, vol. 2013, Article ID 549627, 18 pages, 2013.

[28] M. Kemmerer, F. Finkernagel, M. F. Cavalcante et al., "AMPactivated protein kinase interacts with the peroxisome proliferator-activated receptor delta to induce genes affecting fatty acid oxidation in human macrophages," PLoS ONE, vol. 10, no. 6, Article ID e0130893, 2015.

[29] X. Fang, L. Fang, A. Liu, X. Wang, B. Zhao, and N. Wang, "Activation of PPAR- $\delta$ induces microRNA-100 and decreases the uptake of very low-density lipoprotein in endothelial cells," British Journal of Pharmacology, vol. 172, no. 15, pp. 3728-3736, 2015.

[30] E. Barroso, R. Rodríguez-Rodríguez, M. R. Chacón et al., "PPAR $\beta / \delta$ ameliorates fructose-induced insulin resistance in adipocytes by preventing Nrf2 activation," Biochimica et Biophysica Acta, vol. 1852, no. 5, pp. 1049-1058, 2015.

[31] X. Wang, M. K. Sng, S. Foo et al., "Early controlled release of peroxisome proliferator-activated receptor $\beta / \delta$ agonist GW501516 improves diabetic wound healing through redox modulation of wound microenvironment," Journal of Controlled Release, vol. 197, pp. 138-147, 2015.

[32] S. A. Ham, J. S. Hwang, T. Yoo et al., "Ligand-activated PPAR $\delta$ upregulates $\alpha$-smooth muscle actin expression in human dermal fibroblasts: a potential role for PPAR $\delta$ in wound healing," Journal of Dermatological Science, vol. 80, no. 3, pp. 186-195, 2015.

[33] C. Ozawa, M. Horiguchi, T. Akita et al., "Pulmonary administration of GW0742, a high-affinity peroxisome proliferatoractivated receptor agonist, repairs collapsed alveoli in an elastase-induced mouse model of emphysema," Biological \& Pharmaceutical Bulletin, vol. 39, no. 5, pp. 778-785, 2016.

[34] M. Toral, M. Gómez-Guzmán, R. Jiménez et al., “Chronic peroxisome proliferator-activated receptor $\beta / \delta$ agonist GW0742 prevents hypertension, vascular inflammatory and oxidative status, and endothelial dysfunction in diet-induced obesity," Journal of Hypertension, vol. 33, no. 9, pp. 1831-1844, 2015.

[35] E. Roche, I. Lascombe, H. Bittard, C. Mougin, and S. Fauconnet, "The PPAR $\beta$ agonist L-165041 promotes VEGF mRNA stabilization in HPV18-harboring HeLa cells through a receptorindependent mechanism," Cellular Signalling, vol. 26, no. 2, pp. 433-443, 2014.

[36] J.-H. Park, K.-S. Lee, H.-J. Lim, H. Kim, H.-J. Kwak, and H.Y. Park, "The PPAR $\delta$ ligand L-165041 inhibits vegf-induced angiogenesis, but the antiangiogenic effect is not related to PPARס," Journal of Cellular Biochemistry, vol. 113, no. 6, pp. 1947-1954, 2012.

[37] Y.-J. Liang, J.-H. Jian, C.-Y. Chen, C.-Y. Hsu, C.-Y. Shih, and J.-G. Leu, "L-165,041, troglitazone and their combination treatment to attenuate high glucose-induced receptor for advanced glycation end products (RAGE) expression," European Journal of Pharmacology, vol. 715, no. 1-3, pp. 33-38, 2013.

[38] B. Staels, A. Rubenstrunk, B. Noel et al., "Hepatoprotective effects of the dual peroxisome proliferator-activated receptor alpha/delta agonist, GFT505, in rodent models of nonalcoholic fatty liver disease/nonalcoholic steatohepatitis," Hepatology, vol. 58, no. 6, pp. 1941-1952, 2013.
[39] T. D. Hinds, K. A. Burns, P. A. Hosick et al., "Biliverdin reductase A attenuates hepatic steatosis by inhibition of glycogen synthase kinase (GSK) $3 \beta$ phosphorylation of serine 73 of peroxisome proliferator-activated receptor (PPAR) $\alpha$," The Journal of Biological Chemistry, vol. 291, no. 48, pp. 25179-25191, 2016.

[40] B. Cariou, R. Hanf, S. Lambert-Porcheron et al., "Dual peroxisome proliferator- activated receptor $\alpha / \delta$ agonist GFT505 improves hepatic and peripheral insulin sensitivity in abdominally obese subjects," Diabetes Care, vol. 36, no. 10, pp. 29232930, 2013.

[41] V. Ratziu, S. A. Harrison, S. Francque et al., "Elafibranor, an agonist of the peroxisome proliferator-activated receptor- $\alpha$ and $-\delta$, induces resolution of nonalcoholic steatohepatitis without fibrosis worsening," Gastroenterology, vol. 150, no. 5, pp. 11471159.e5, 2016.

[42] C. Janani and B. Ranjitha Kumari, "PPAR gamma gene-a review, Diabetes \& Metabolic Syndrome: Clinical Research \& Reviews, vol. 9, no. 1, pp. 46-50, 2015.

[43] J. N. Feige, L. Gelman, L. Michalik, B. Desvergne, and W. Wahli, "From molecular action to physiological outputs: peroxisome proliferator-activated receptors are nuclear receptors at the crossroads of key cellular functions," Progress in Lipid Research, vol. 45, no. 2, pp. 120-159, 2006.

[44] G. Medina-Gomez, S. L. Gray, L. Yetukuri et al., "PPAR gamma 2 prevents lipotoxicity by controlling adipose tissue expandability and peripheral lipid metabolism," PLoS Genetics, vol. 3, no. 4, pp. 634-647, 2007.

[45] G. Medina-Gomez, S. Gray, and A. Vidal-Puig, "Adipogenesis and lipotoxicity: role of peroxisome proliferator-activated receptor $\gamma$ (PPAR $\gamma)$ and PPAR $\gamma$ coactivator-1 (PGC1)," Public Health Nutrition, vol. 10, no. 10 A, pp. 1132-1137, 2007.

[46] U. Kintscher and R. E. Law, "PPAR $\gamma$-mediated insulin sensitization: the importance of fat versus muscle," American Journal of Physiology-Endocrinology and Metabolism, vol. 288, no. 2, pp. E287-E291, 2005.

[47] N. Marx, T. Bourcier, G. K. Sukhova, P. Libby, and J. Plutzky, "PPAR $\gamma$ activation in human endothelial cells increases plasminogen activator inhibitor type- 1 expression: $\operatorname{PPAR} \gamma$ as a potential mediator in vascular disease," Arteriosclerosis, Thrombosis, and Vascular Biology, vol. 19, no. 3, pp. 546-551, 1999.

[48] M. Heim, J. Johnson, F. Boess et al., "Phytanic acid, a natural peroxisome proliferator-activated receptor (PPAR) agonist, regulates glucose metabolism in rat primary hepatocytes," The FASEB Journal, vol. 16, no. 7, pp. 718-720, 2002.

[49] A. Krishnaswami, S. Ravi-Kumar, and J. M. Lewis, "Thiazolidinediones: a 2010 perspective," The Permanente Journal, vol. 14, pp. 64-72, 2010.

[50] J. Dormandy, M. Bhattacharya, and A.-R. Van Troostenburg De Bruyn, "Safety and tolerability of pioglitazone in highrisk patients with type 2 diabetes: an overview of data from PROactive," Drug Safety, vol. 32, no. 3, pp. 187-202, 2009.

[51] S. E. Nissen and K. Wolski, "Effect of rosiglitazone on the risk of myocardial infarction and death from cardiovascular causes," The New England Journal of Medicine, vol. 356, no. 24, pp. 24572471, 2007.

[52] M. A. Deeg and M. H. Tan, "Pioglitazone versus rosiglitazone: effects on lipids, lipoproteins, and apolipoproteins in head-tohead randomized clinical studies," PPAR Research, vol. 2008, Article ID 520465, 6 pages, 2008. 
[53] J. H. Choi, A. S. Banks, T. M. Kamenecka et al., "Antidiabetic actions of a non-agonist PPAR $\gamma$ ligand blocking Cdk5mediated phosphorylation," Nature, vol. 477, no. 7365, pp. 477481, 2011.

[54] X. Liu, O. Kunert, M. Blunder et al., "Polyyne hybrid compounds from notopterygium incisum with peroxisome proliferator-activated receptor gamma agonistic effects," Journal of Natural Products, vol. 77, no. 11, pp. 2513-2521, 2014.

[55] L. Wang, B. Waltenberger, E.-M. Pferschy-Wenzig et al., "Natural product agonists of peroxisome proliferator-activated receptor gamma (PPAR $\gamma)$ : a review," Biochemical Pharmacology, vol. 92, no. 1, pp. 73-89, 2014.

[56] J. W. Lee, P. J. Bajwa, M. J. Carson et al., "Fenofibrate represses interleukin-17 and interferon- $\gamma$ expression and improves colitis in interleukin-10-deficient mice," Gastroenterology, vol. 133, no. 1, pp. 108-123, 2007.

[57] Y.-P. Huang and N. W. Chang, "PPAR $\alpha$ modulates gene expression profiles of mitochondrial energy metabolism in oral tumorigenesis," BioMedicine, vol. 6, no. 1, article 3, 2016.

[58] G. Sarnelli, A. D’Alessandro, T. Iuvone et al., "Palmitoylethanolamide modulates inflammation-associated Vascular Endothelial Growth Factor (VEGF) signaling via the akt/mtor pathway in a selective Peroxisome Proliferator-Activated Receptor Alpha (PPAR- $\alpha$ )-dependent manner," PLoS One, vol. 11, no. 5, Article ID e0156198, 2016.

[59] K. Chandran, S. Goswami, and N. Sharma-Walia, "Implications of a peroxisome proliferator-activated receptor alpha (PPAR $\alpha$ ) ligand clofibrate in breast cancer," Oncotarget, vol. 7, no. 13, pp. 15577-15599, 2015.

[60] K. Wejksza, C. Lee-Chang, M. Bodogai et al., "Cancer-produced metabolites of 5-lipoxygenase induce tumor-evoked regulatory B cells via peroxisome proliferator-activated receptor $\alpha$," The Journal of Immunology, vol. 190, no. 6, pp. 2575-2584, 2013.

[61] J. Gao, S. Yuan, J. Jin, J. Shi, and Y. Hou, "PPAR $\alpha$ regulates tumor progression, foe or friend?" European Journal of Pharmacology, vol. 765, pp. 560-564, 2015.

[62] J. Gao, Q. Liu, Y. Xu et al., "PPAR $\alpha$ induces cell apoptosis by destructing Bcl2," Oncotarget, vol. 6, no. 42, pp. 44635-44642, 2015.

[63] N. Zhang, E. S. H. Chu, J. Zhang et al., "Peroxisome proliferator activated receptor alpha inhibits hepatocarcinogenesis through mediating NF- $\kappa$ B signaling pathway," Oncotarget, vol. 5, no. 18, pp. 8330-8340, 2014.

[64] T. Aoki, "Current status of carcinogenicity assessment of peroxisome proliferator-activated receptor agonists by the US FDA and a mode-of-action approach to the carcinogenic potential," Journal of Toxicologic Pathology, vol. 20, no. 4, pp. 197-202, 2008.

[65] I. M. Pruimboom-Brees, O. Francone, J. C. Pettersen et al., “The development of subcutaneous sarcomas in rodents exposed to peroxisome proliferators agonists: hypothetical mechanisms of action and de-risking attitude," Toxicologic Pathology, vol. 40, no. 5, pp. 810-818, 2012.

[66] H. K. Park, H. K. Kim, H.-G. Kim et al., "Expression of peroxisome proliferator activated receptor gamma in prostatic adenocarcinoma," Journal of Korean Medical Science, vol. 30, no. 5, pp. 533-541, 2015.

[67] S. Polvani, M. Tarocchi, S. Tempesti, L. Bencini, and A. Galli, "Peroxisome proliferator activated receptors at the crossroad of obesity, diabetes, and pancreatic cancer," World Journal of Gastroenterology, vol. 22, no. 8, pp. 2441-2459, 2016.
[68] J. D. Coleman, J. T. Thompson, R. W. Smith III, B. Prokopczyk, and J. P. Vanden Heuvel, "Role of peroxisome proliferatoractivated receptor $\beta / \delta$ and B-cell lymphoma- 6 in regulation of genes involved in metastasis and migration in pancreatic cancer cells," PPAR Research, vol. 2013, Article ID 121956, 11 pages, 2013.

[69] H. V. Reddi, P. Madde, L. A. Marlow et al., "Expression of the PAX8/PPAR $\gamma$ fusion protein is associated with decreased neovascularization in vivo: impact on tumorigenesis and disease prognosis," Genes and Cancer, vol. 1, no. 5, pp. 480-492, 2010.

[70] D. Rovito, G. Gionfriddo, I. Barone et al., "Ligand-activated PPAR $\gamma$ downregulates CXCR4 gene expression through a novel identified PPAR response element and inhibits breast cancer progression," Oncotarget, 2016.

[71] S. Das Gupta, S. Sae-Tan, J. Wahler et al., "Dietary $\gamma$-tocopherolrich mixture inhibits estrogen-induced mammary tumorigenesis by modulating estrogen metabolism, antioxidant response, and PPAR $\gamma$," Cancer Prevention Research, vol. 8, no. 9, pp. 807816, 2015.

[72] G. Skelhorne-gross, A. L. Reid, A. J. Apostoli et al., "Stromal adipocyte PPAR $\gamma$ protects against breast tumorigenesis," Carcinogenesis, vol. 33, no. 7, pp. 1412-1420, 2012.

[73] C. A. McAlpine, Y. Barak, I. Matise, and R. T. Cormier, "Intestinal-specific PPAR $\gamma$ deficiency enhances tumorigenesis in ApcMin/+ mice," International Journal of Cancer, vol. 119, no. 10, pp. 2339-2346, 2006.

[74] L. Wu, C. Yan, M. Czader et al., "Inhibition of PPAR $\gamma$ in myeloid-lineage cells induces systemic inflammation, immunosuppression, and tumorigenesis," Blood, vol. 119, no. 1, pp. 115126, 2012.

[75] Y. Susaki, M. Inoue, M. Minami et al., "Inhibitory effect of PPAR $\gamma$ on NR0B1 in tumorigenesis of lung adenocarcinoma," International Journal of Oncology, vol. 41, no. 4, pp. 1278-1284, 2012.

[76] J. M. Peters, F. J. Gonzalez, and R. Müller, "Establishing the Role of PPAR $\beta / \delta$ in Carcinogenesis," Trends in Endocrinology and Metabolism, vol. 26, no. 11, pp. 595-607, 2015.

[77] A. Abdollahi, C. Schwager, J. Kleeff et al., "Transcriptional network governing the angiogenic switch in human pancreatic cancer," Proceedings of the National Academy of Sciences of the United States of America, vol. 104, no. 31, pp. 12890-12895, 2007.

[78] D. Wang and R. N. DuBois, "PPAR $\delta$ and PGE2 signaling pathways communicate and connect inflammation to colorectal cancer," Inflammation and Cell Signaling, vol. 1, no. 4, 2014.

[79] S. Beyaz and Ö. H. Yilmaz, "Molecular pathways: dietary regulation of stemness and tumor initiation by the PPAR- $\delta$ pathway," Clinical Cancer Research, vol. 22, no. 23, pp. 5636-5641, 2016.

[80] J. Tomas, C. Mulet, A. Saffarian et al., "High-fat diet modifies the PPAR- $\gamma$ pathway leading to disruption of microbial and physiological ecosystem in murine small intestine," Proceedings of the National Academy of Sciences, vol. 113, no. 40, pp. E5934E5943, 2016.

[81] X. Wang, G. Wang, Y. Shi et al., "PPAR-delta promotes survival of breast cancer cells in harsh metabolic conditions," Oncogenesis, vol. 5, no. 6, article e232, 2016.

[82] O. Margalit, D. Wang, and R. N. DuBois, "PPAR $\gamma$ agonists target aromatase via both PGE2 and BRCA1," Cancer Prevention Research, vol. 5, no. 10, pp. 1169-1172, 2012.

[83] K. Subbaramaiah, L. R. Howe, X. K. Zhou et al., "Pioglitazone, a PPAR $\gamma$ agonist, suppresses CYP19 transcription: evidence for involvement of 15-hydroxyprostaglandin dehydrogenase and BRCA1," Cancer Prevention Research, vol. 5, no. 10, pp. 11831194, 2012. 
[84] S. A. Ham, T. Yoo, J. S. Hwang et al., "Ligand-activated $\operatorname{PPAR} \delta$ modulates the migration and invasion of melanoma cells by regulating Snail expression," American Journal of Cancer Research, vol. 4, no. 6, pp. 674-682, 2014.

[85] A. Laganà, S. Vitale, A. Nigro et al., "Pleiotropic actions of Peroxisome Proliferator-Activated Receptors (PPARs) in dysregulated metabolic homeostasis, inflammation and cancer: current evidence and future perspectives," International Journal of Molecular Sciences, vol. 17, no. 7, article no. 999, 2016.

[86] M. Terrasi, V. Bazan, S. Caruso et al., "Effects of PPAR $\gamma$ agonists on the expression of leptin and vascular endothelial growth factor in breast cancer cells," Journal of Cellular Physiology, vol. 228, no. 6, pp. 1368-1374, 2013.

[87] V. Vetvicka, A. S. Laganà, F. M. Salmeri et al., "Regulation of apoptotic pathways during endometriosis: from the molecular basis to the future perspectives," Archives of Gynecology and Obstetrics, vol. 294, no. 5, pp. 897-904, 2016.

[88] A. S. Laganà, O. Triolo, F. M. Salmeri et al., "Natural Killer T cell subsets in eutopic and ectopic endometrium: a fresh look to a busy corner," Archives of Gynecology and Obstetrics, pp. 1-9, 2016.

[89] V. Sofo, M. Götte, A. S. Laganà et al., "Correlation between dioxin and endometriosis: an epigenetic route to unravel the pathogenesis of the disease," Archives of Gynecology and Obstetrics, vol. 292, no. 5, pp. 973-986, 2015.

[90] S. G. Vitale, P. Rossetti, F. Corrado et al., "How to achieve highquality oocytes? The key role of myo-inositol and melatonin," International Journal of Endocrinology, vol. 2016, Article ID 4987436, 9 pages, 2016.

[91] A. Cianci, N. Colacurci, A. M. Paoletti et al., "Soy isoflavones, inulin, calcium, and vitamin D3 in post-menopausal hot flushes: An Observational Study," Clinical and experimental obstetrics \& gynecology, vol. 42, no. 6, pp. 743-745, 2015.

[92] F. Colonese, A. S. Laganà, E. Colonese et al., "The pleiotropic effects of vitamin D in gynaecological and obstetric diseases: an overview on a hot topic," BioMed Research International, vol. 2015, Article ID 986281, 11 pages, 2015.

[93] C. Paul, A. S. Laganà, P. Maniglio, O. Triolo, and D. M. Brady, "Inositol's and other nutraceuticals' synergistic actions counteract insulin resistance in polycystic ovarian syndrome and metabolic syndrome: state-of-the-art and future perspectives," Gynecological Endocrinology, vol. 32, no. 6, pp. 431-438, 2016. 


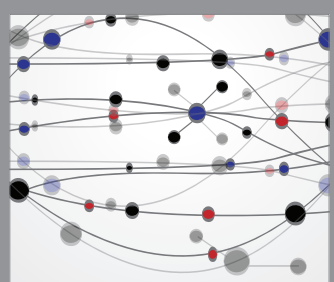

The Scientific World Journal
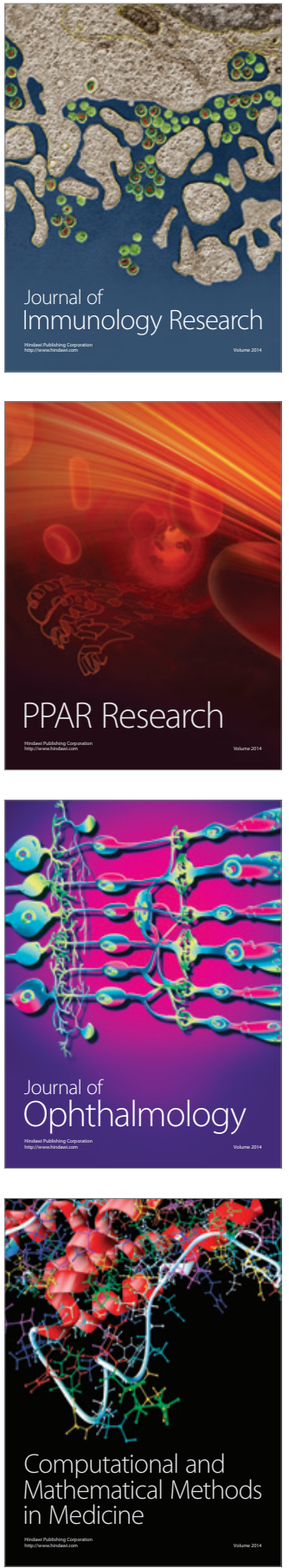

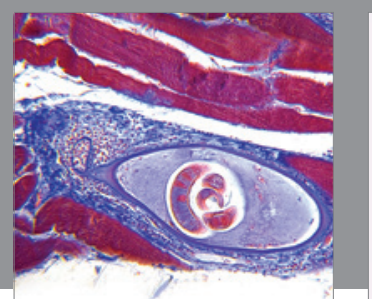

Gastroenterology Research and Practice

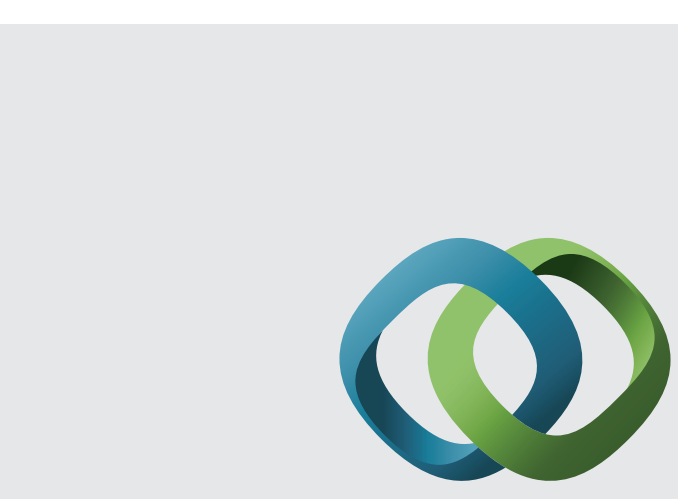

\section{Hindawi}

Submit your manuscripts at

http://www.hindawi.com
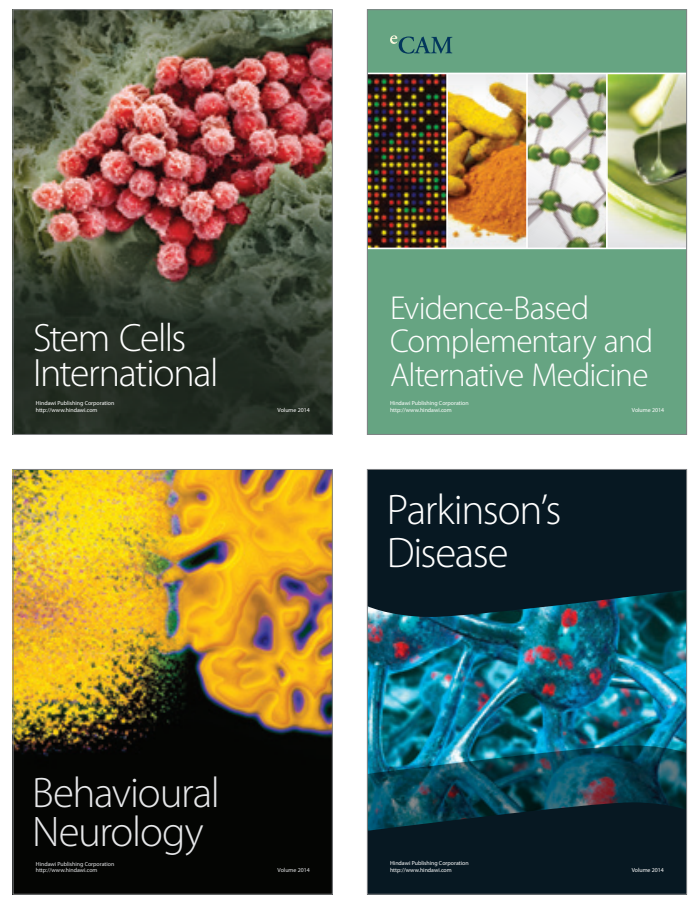
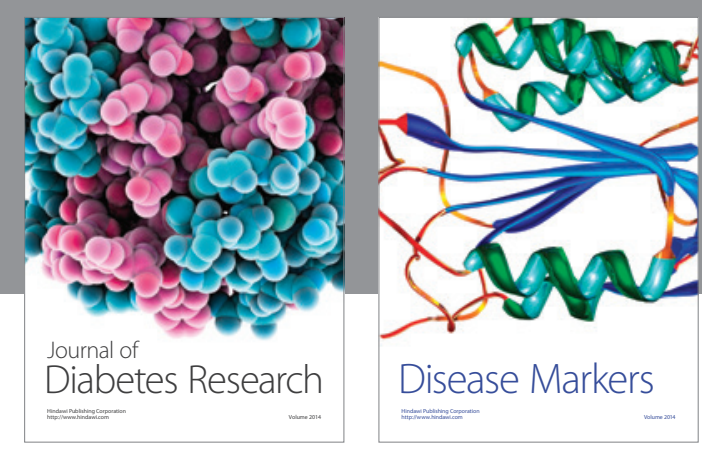

Disease Markers
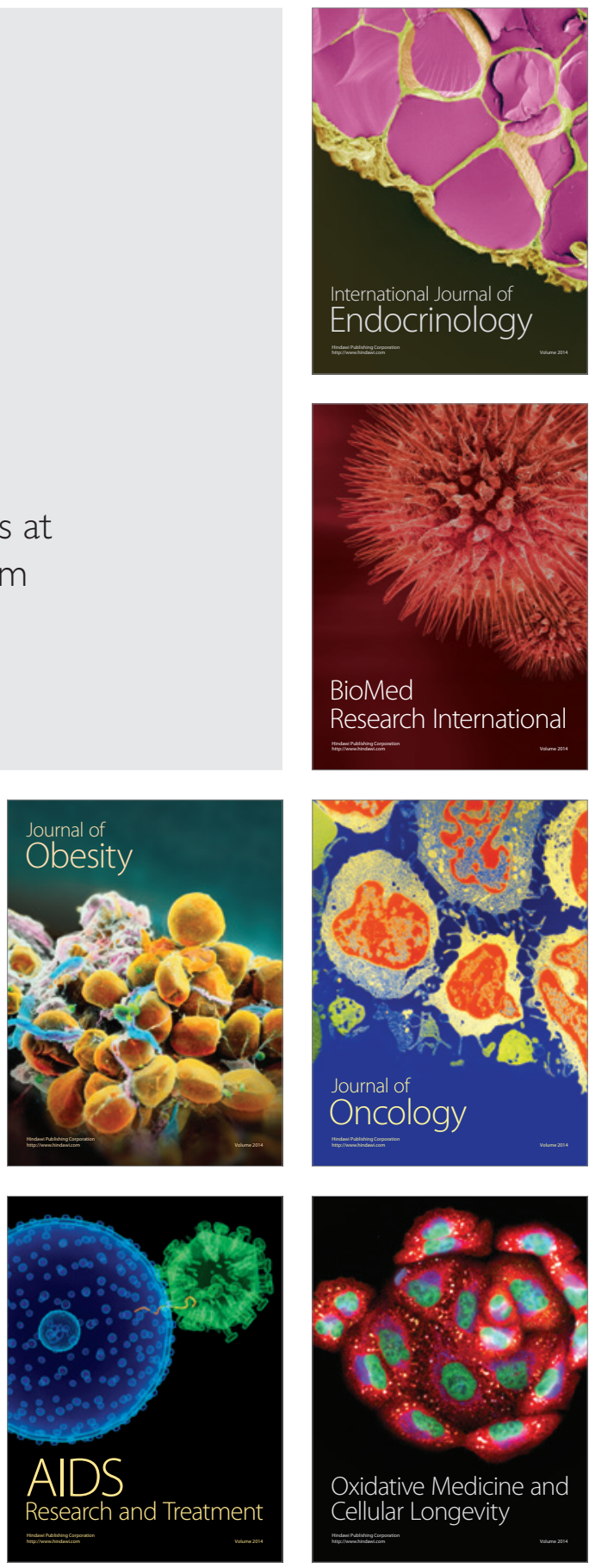